\title{
B-Amyloid Treatment Sensitizes Mice to Amphetamine-Induced Locomotion but Reduces Response to Caffeine
}

\author{
Oscar P. Dall'Igna anselmo Hoffmann ${ }^{a}$ Adriana L. da Silva ${ }^{a}$ \\ Diogo O. Souza ${ }^{a}$ Diogo R. Larab \\ a Departamento de Bioquímica, Instituto de Ciencias Basicas da Saude, Universidade Federal do Rio Grande do Sul, \\ e ${ }^{\text {b}}$ Faculdade de Biociências, Pontifícia Universidade Católica do Rio Grande do Sul, Porto Alegre, Brazil
}

\author{
Key Words \\ Alzheimer's disease - Amphetamine $\cdot \beta$-Amyloid . \\ Caffeine $\cdot$ Locomotion $\cdot$ MK-801
}

\begin{abstract}
Backgroud: Psychosis frequently occurs in Alzheimer's disease (AD), being associated with more severe cognitive decline, but the underlying mechanisms are unknown. Objective: To investigate the effect of centrally administered $\beta$-amyloid peptide, a model for $A D$, in the locomotor response to amphetamine, caffeine and MK801 , which are psychoactive drugs related to neurochemical changes occurring in psychosis. Methods: Mice were intracerebroventricularly injected with $\beta$-amyloid (25-35), and after 1 week they were tested in the passive avoidance, spontaneous alternation and locomotor tasks. Results: Besides impaired performance in inhibitory avoidance and spontaneous alternation tasks, $\beta$-amyloid-treated mice showed increased spontaneous locomotion, augmented response to amphetamine $(1.5 \mathrm{mg} /$ $\mathrm{kg})$, blunted response to caffeine $(30 \mathrm{mg} / \mathrm{kg}$ ) and no difference in MK-801 (0.25 mg/kg)-induced locomotor activation when compared to its respective control. Conclu-
\end{abstract}

\section{KARGER}

Fax + 41613061234

E-Mail karger@karger.ch

www.karger.com
(C) 2004 S. Karger AG, Basel

1660-2854/04/0011-0038\$21.00/0

Accessible online at:

www. karger.com/ndd sion: These results are compatible with the hypothesis that $\beta$-amyloid peptide may predispose to psychotic symptoms of $A D$ by increasing sensitivity of the dopaminergic system, possibly related to a decreased adenosinergic inhibitory tone.

Copyright $\odot 2004$ S. Karger AG, Base

\section{Introduction}

Psychosis affects up to $30 \%$ of the Alzheimer's disease patients (AD), with delusions and hallucinations as the most frequently expressed psychotic symptoms [1]. Several studies have shown that psychotic patients have more rapid cognitive decline when compared to controls [2]. However, there is no consistent explanation for the pathophysiology of psychosis in AD patients in the few available studies, in which a small number of brain regions, and neuropathological and neurochemical parameters were investigated [1].

Animal models have been useful for studying the neurobiology of psychosis and AD. The behavioral effects of N-methyl- $D$ aspartate (NMDA) [3] receptor antagonists, such as phencyclidine and MK-801, are currently ac-

Oscar P. Dall'Igna

Departamento de Bioquímica, ICBS, UFRGS

Rua Ramiro Barcelos, 2600-Anexo

90035-033 Porto Alegre (Brazil)

Tel. +55 51 33165557, Fax +55 51 33165540, E-Mail oscar.dalligna@ufrgs.br 
cepted pharmacological models of psychosis. NMDA antagonists produce positive, negative and disorganization symptoms in healthy subjects, which are mostly indistinguishable from those observed in schizophrenic patients [4]. Regarding the dopaminergic system, most antipsychotic drugs are dopamine $\mathrm{D}_{2}$ receptor antagonists [5], and dopaminergic agonists such as amphetamine are classic models for psychosis [6]. Caffeine, a non-selective adenosine antagonist, is another psychostimulant, possibly by indirectly stimulating the dopaminergic system [7, 8]. In animal models, hyperlocomotor response produced by amphetamine and NMDA receptor antagonists is the most common behavioral parameter both to predict putative antipsychotics [9] and to evaluate predisposing conditions to psychotic states [10].

Neurofibrillary tangles and parenchymal deposition of $\beta$-amyloid in senile plaques are pathological hallmarks of $\mathrm{AD}$, and their extension correlate with neuronal damage and cognitive deficits in the disease [11]. Central administration of the $\beta$-amyloid (25-35) fragment $\left(\beta_{25-35}\right)$ in animal brain causes histological, biochemical and memory alterations, composing an animal model of $\mathrm{AD}$ [12]. There are currently few data concerning spontaneous and drug-induced locomotion in mice centrally treated with $\beta_{25-35}$. We investigated the effect of $\beta_{25-35}$ administration on locomotor behavior by interfering with the glutamatergic, dopaminergic and adenosinergic systems.

\section{Materials and Methods}

\section{Animals}

Experiments were performed with male adult mice 3-4 months old (35-45 g; CF1 strain) maintained in our own animal facilities under controlled environment $\left(23 \pm 2{ }^{\circ} \mathrm{C}, 12\right.$-hour light/dark cycle, free access to food and water). All behavioral experiments were conducted between 10:00 a.m. and 2:00 p.m. and were in accordance with our institutional animal care protocols. Animals were used only once.

\section{Drugs and Administration Procedure}

MK-801, amphetamine, caffeine and $\beta_{25-35}$ were purchased from Sigma (St. Louis, Mo., USA). The $\beta_{25-35}$ peptide was dissolved in bidistilled water at a concentration of $2 \mathrm{mg} / \mathrm{ml}$ and stored at $-20^{\circ} \mathrm{C}$ until use. The peptide solutions were thawed and aggregated by incubation for 4 days at $37^{\circ} \mathrm{C}$ in a $1 \mathrm{mg} / \mathrm{ml}$ solution in bidistilled water, providing the formation of birefringent fibril-like structures and amorphous globular aggregates. The $\beta_{25-35}$ peptide was then administered intracerebroventricularly. Mice were anesthetized with $60 \mathrm{mg} /$ $\mathrm{kg}$ of thiopental, and a 28 -gauge 5 -mm-long stainless-steel needle was inserted unilaterally $1 \mathrm{~mm}$ to the right of the midline point equidistant from each eye, at an equal distance between the eyes and the ears and perpendicular to the plane of the skull $(2.5 \mathrm{~mm}$ depth). Peptide or vehicle $(3 \mu \mathrm{l})$ was delivered within approximately $3 \mathrm{~s}$ intracerebro- ventricularly. Administration had been confirmed by injecting methylene blue in preliminary experiments. Other drugs were injected intraperitoneally at a volume of $10 \mathrm{ml} / \mathrm{kg}$.

\section{Spontaneous Alternation}

Spontaneous alternation performance was assessed 8 days after $\beta$-amyloid administration in the Y-maze. Each arm was $30 \mathrm{~cm}$ long, $20 \mathrm{~cm}$ in height and $6 \mathrm{~cm}$ wide, and converged to an equal angle. Each mouse was placed at the end of one arm and allowed to freely move through the maze during $8 \mathrm{~min}$. The series of arm entries was recorded visually. An alternation was defined as entries in all three arms on consecutive occasions. The percentage of alternation was calculated (total alternation/total arm entries -2 ).

\section{Locomotor Activity}

Locomotor activity was assessed 8 days after $\beta$-amyloid administration. Mice were randomly allocated to individual triangular boxes with rounded corners $\left(800 \mathrm{~cm}^{2}\right)$ placed on the floor of a soundproof and diffusely illuminated room. Motor activity of 8 mice was recorded simultaneously by a video-computerized system, with image analysis at 4 frames per second. The software tracked the animals by distinguishing their white color from the black background of the box floor, registering $\mathrm{X}$ and $\mathrm{Y}$ horizontal coordinates. The method was set to examine horizontal locomotor activity, ignoring small movements like breathing, head and tail actions, and tremors. Animals had not been previously habituated to the boxes and were observed for a total of $4 \mathrm{~h}$, with data divided into 10 -min blocks. MK- $801(0.25 \mathrm{mg} / \mathrm{kg})$, amphetamine $(1.5 \mathrm{mg} / \mathrm{kg})$, caffeine $(30 \mathrm{mg} / \mathrm{kg})$ or saline was administered intraperitoneally to mice after a 1-hour habituation period. Pilot studies in our laboratory showed that these doses produce an increase in locomotion that is not in excess of the level of locomotion seen during the habituation period; therefore further enhancement of locomotion would not be masked by a ceiling effect.

\section{Inhibitory Avoidance}

Long-term memory was examined 9 days after $\beta$-amyloid administration using step-down inhibitory avoidance. The session apparatus is a $50 \times 25 \times 25 \mathrm{~cm}$ plastic box with a platform $(2 \mathrm{~cm}$ high and $4 \times 6 \mathrm{~cm}$ wide) at the center of the training apparatus. The floor of the apparatus was made of parallel $0.1-\mathrm{cm}$-caliber stainless steel bars spaced $1.0 \mathrm{~cm}$ apart. In training session, the animals were placed on the platform and the latency to step down the four paws on the grid was measured with a device; upon stepping down, mice received a 0.2-mA, 2-second scrambled foot shock. Test session step-down latency $24 \mathrm{~h}$ later was taken as measure of retention, to a ceiling time of $180 \mathrm{~s}$. No foot shock was given in the test session.

\section{Statistical Analysis}

Locomotion and spontaneous alternation are expressed as means \pm SEM and step-down latency is expressed in terms of medians and interquartile ranges. Spontaneous alternation was analyzed using one-way ANOVA. Step-down latency was analyzed using the MannWhitney test followed by the Kruskal-Wallis nonparametric test. Differences between time blocks in locomotor activity were assessed by one-way ANOVA. Comparisons between locomotor activities at different time points were analyzed using a general linear model with repeated measures (drug treatment vs. time) with time as the repeated measure. Duncan's post hoc test was used to determine differences among specific groups. A p value $<0.05$ was considered statistically significant. 


\section{Results}

Confirming previous observations [13], central administration of $\beta_{25-35}$ affected performance in the inhibitory avoidance test for long-term memory, as shown by the reduced step-down latency (fig. 1a) as well as spontaneous alternation performance in the Y-maze test (fig. 1b). There was no difference in total arm entries between $\beta_{25-35}$ and sham-operated mice ( $\mathrm{n}=16$ per group).

Mice injected with $\beta_{25-35}$ showed higher spontaneous locomotion during the whole 4-hour experiment (fig. 2). Low-dose amphetamine $(1.5 \mathrm{mg} / \mathrm{kg})$ nonsignificantly increased spontaneous locomotion; however, $\beta_{25-35}$-treated mice presented a significantly higher locomotor response to amphetamine when compared to sham-operated mice $[F(1,12)=9.125 ; \mathrm{p}<0.05 ;$ fig. $2 \mathrm{a}, 3]$. Caffeine $(30 \mathrm{mg} / \mathrm{kg})$ caused significant hyperlocomotion in control animals, whereas there was no increase in activity of mice treated with $\beta_{25-35}[F(1,14)=6.140 ; p<0.05$; fig. 2b, 3]. Both sham- and $\beta_{25-35}$-operated mice had a similar hyperlocomotion response to MK-801 $(0.25 \mathrm{mg} / \mathrm{kg})$ administration $[F(1,14)=0.619 ; p>0.05]$ compared to its respective control group (fig. 2c, 3), but $\beta_{25-35}$ treated mice showed nonsignificantly increased locomotion compared to the sham + MK-801 group ( $\mathrm{n}=8$ per group).

\section{Discussion}

These results show a distinctive response of $\beta_{25-35-}$ treated mice in a locomotor activity task, characterized by higher basal locomotor activity, enhanced response to low-dose amphetamine and reduced response to caffeine, whereas the response to MK-801 was minimally altered. This profile supports the notion that $\beta$-amyloid accumulation may underlie the clinical observation of psychotic symptoms in $\mathrm{AD}$, which are possibly associated with a hyperdopaminergic state. Moreover, the blunted response to caffeine suggests a reduced striatal adenosinergic tone, which can contribute to the increased sensitivity to amphetamine due to adenosine-dopamine interactions [7].

Cerebral $\beta_{25-35}$ microinjection produces both $\beta$-amyloid deposition and amnesia, which is considered a valid model for the neuropathology of AD [14], being mostly equivalent to complete $\beta$-amyloid (1-40) peptide while studying its neurotoxic effects and putative neuroprotective agents in vivo [15]. As previously described, intracerebroventricular microinjection of aggregated $\beta_{25-35}$ affects the whole brain, particularly the frontoparietal cortex, hippocampal formation, corpus callosum, cingulum

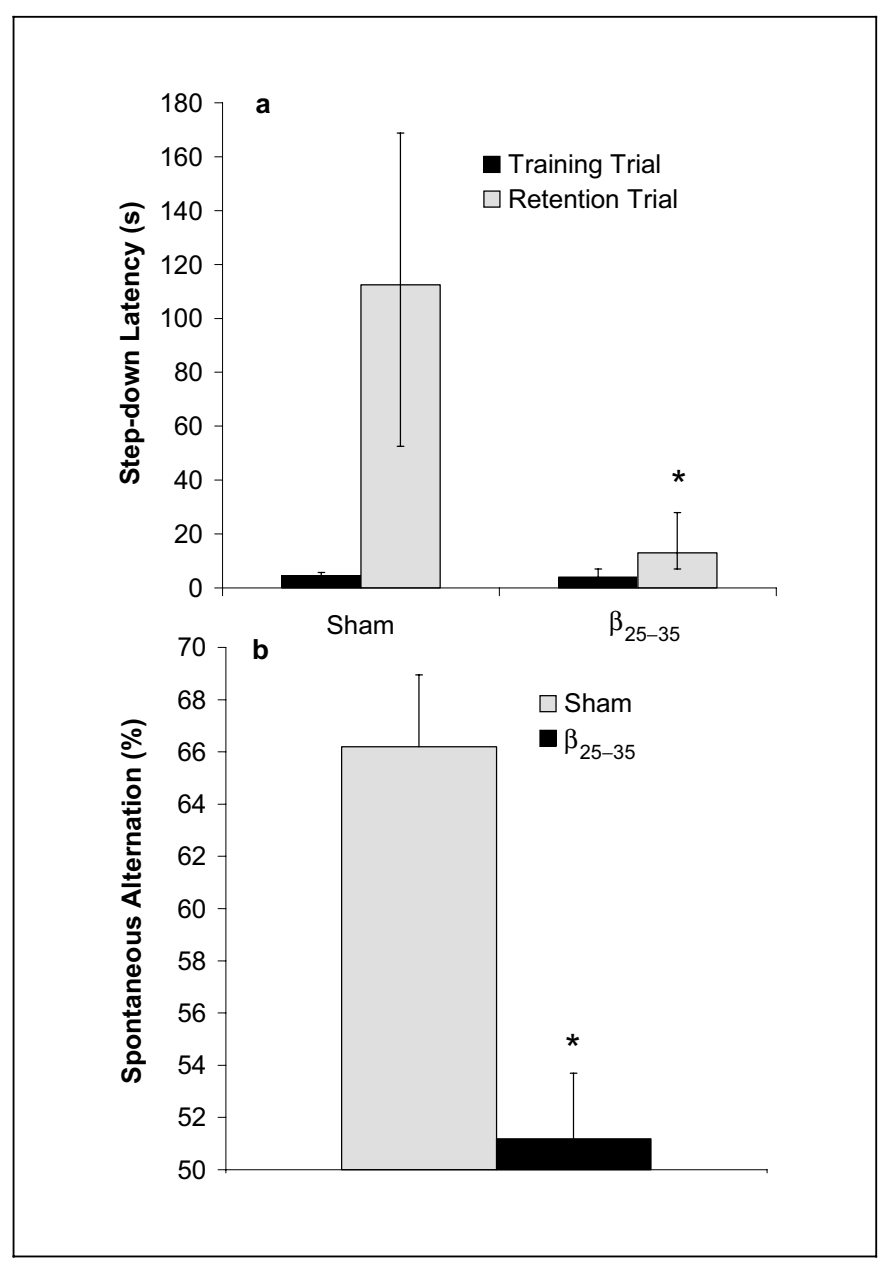

Fig. 1. $\beta$-Amyloid impairs performance in memory tasks. Time latency in the inhibitory avoidance task (a) and spontaneous alternation in the Y-maze (b) of $\beta$-amyloid 25-35 (3 nmol)- or sham-operated mice are shown. ${ }^{*} \mathrm{p}<0.05$ (Kruskall-Wallis test for inhibitory avoidance, $\mathbf{a}$, or one-way ANOVA for spontaneous alternation, $\mathbf{b}$; $\mathrm{n}=16$ for both groups).

and striatum, with significant neuronal loss in the hippocampus CA3 region and cortex, both ipsi- and contralaterally [13]. This distribution correlates well with the diffuse and heterogeneous pattern encountered in AD patients, in whom the amount of $\beta$-amyloid, mainly in the entorhinal cortex and in the subiculum, correlates with cognitive decline [16]. The present results suggest that in addition to the cognitive symptoms, also the behavioral alterations found in $\mathrm{AD}$ patients (particularly psychotic symptoms and increased psychomotor activity) can be modeled by $\beta_{25-35}$ microinjection. However, the lack of histopathological evaluation in our study is a limitation, not allowing a 
Fig. 2. Effect of amphetamine, caffeine or MK-801 on locomotor activity in sham- and $\beta$-amyloid-treated mice. After $1 \mathrm{~h}$ of habituation, mice were treated with saline, amphetamine $(1.5 \mathrm{mg} / \mathrm{kg}$; a), caffeine $(30 \mathrm{mg} / \mathrm{kg}$; b) or MK-801 $(0.25 \mathrm{mg} / \mathrm{kg}$; c), and locomotor activity was recorded for 3 further hours. $* \mathrm{p}<0.05$ vs. the respective control; ${ }^{* *} \mathrm{p}<$ 0.05 vs. sham + amphetamine or caffeine group $(\mathrm{p}<0.05)$ in the general linear model with repeated measures (drug treatment vs. time) with time as the repeated measure $(\mathrm{n}=$ 8 for all groups).
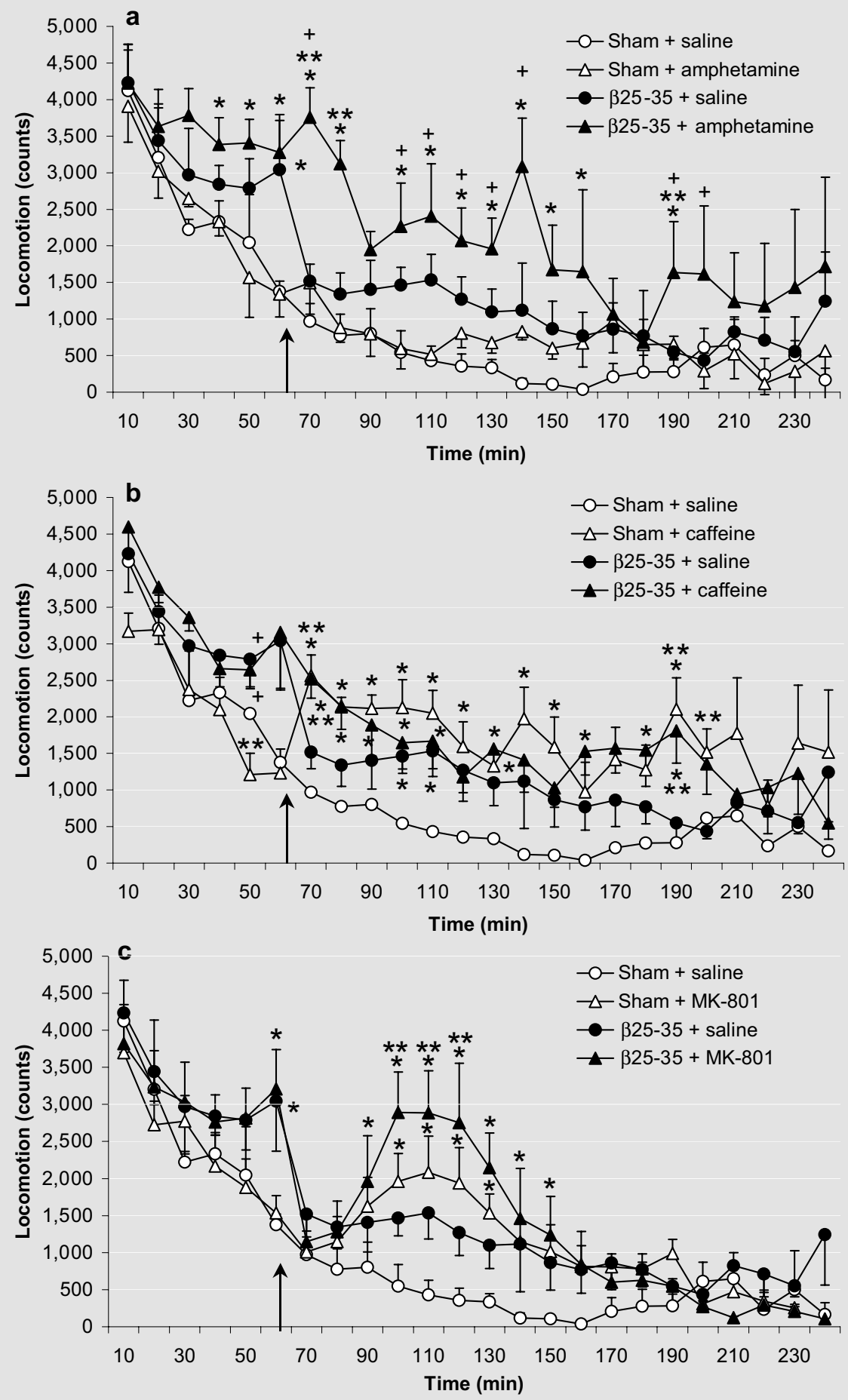
Fig. 3. Net locomotor activity of mice treated with amphetamine, caffeine and MK-801. Locomotor activity for $90 \mathrm{~min}$ after saline treatment in sham- and $\beta$-amyloidtreated mice is shown as total activity. These data were subtracted from the locomotor activity of the equivalent time period after treatment with amphetamine $(1.5 \mathrm{mg} / \mathrm{kg})$, caffeine $(30 \mathrm{mg} / \mathrm{kg})$ or MK-801 $(0.25 \mathrm{mg} / \mathrm{kg})$ in their respective groups. ${ }^{*} \mathrm{p}<0.05$ vs. their respective controls (one-way ANOVA; Duncan post-hoc test; $\mathrm{n}=8$ for all groups).

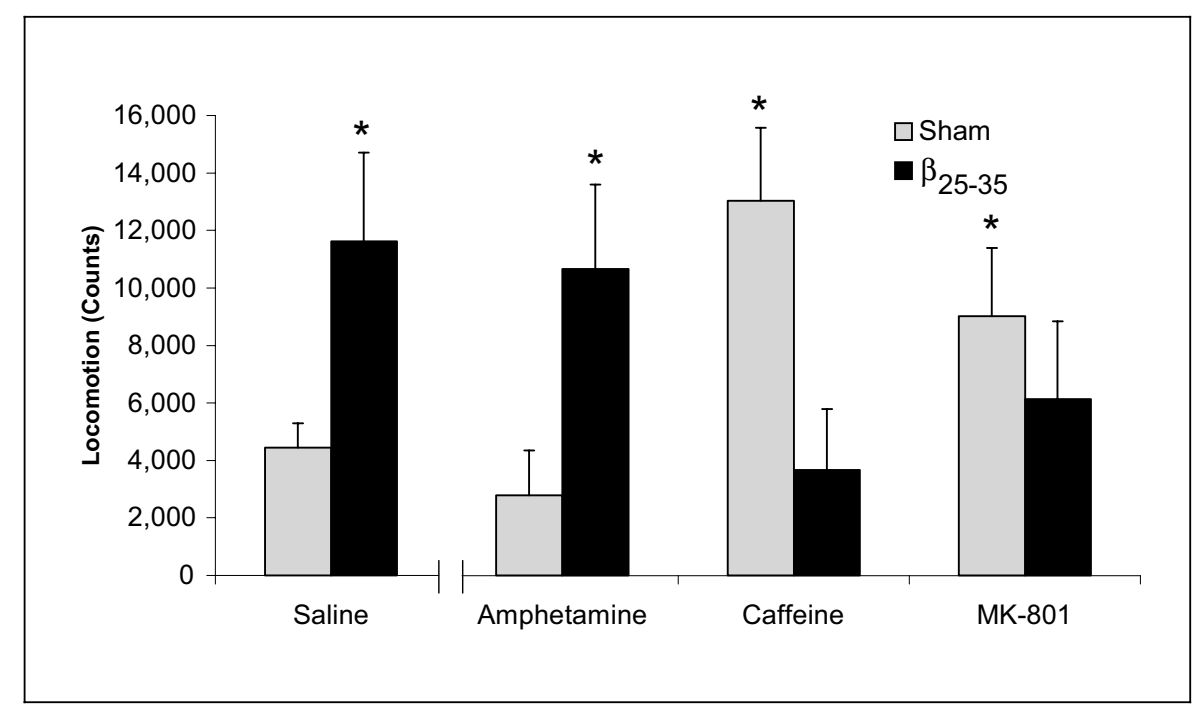

correlation between the behavioral responses to discrete brain regions.

The augmented spontaneous locomotion of mice treated with $\beta_{25-35}$ can be explained by three different factors (occurring either alone or in combination): (i) an increased dopaminergic tone, as suggested by the increased response to amphetamine; (ii) a decreased adenosinergic tone, as suggested by the reduced response to caffeine, which blocks A1 and A2A receptors of the inhibitory neuromodulator adenosine [8], and (iii) increased anxiety response to mild stress associated with the new environment [17]. In contrast to our model, mice overexpressing $\beta$-amyloid precursor protein showed lower exploratory behavior in a 20-min open-field trial [18], and mice treated with $\beta$-amyloid $1-40$ showed normal behavior in a similar 10-min task [14]. This discrepancy possibly derives from the short period of analysis in those works, since our results showed that higher locomotor activity is mostly expressed after $30 \mathrm{~min}$. It is noteworthy that mice treated with $\beta$-amyloid did habituate to some degree to the novel environment, but maintained a higher locomotion throughout the whole 4-hour period, suggesting a genuine hyperactive state rather than a delayed habituation response secondary to spatial memory impairment.

There may be a relationship between the increased response to amphetamine, which induces dopamine release, and the blunted response to caffeine, which blocks adenosine receptors. Adenosine is an important inhibitory neuromodulator, inhibiting the release of several neurotransmitters, including glutamate, acetylcholine and dopamine [7]. Adenosine receptors form heterodimers with dopamine receptors, exerting an inhibitory role [19]. Adenosine receptor agonists counteract the effect of several psychostimulants, including amphetamine, whereas adenosine receptor antagonists, such as caffeine, potentiate hyperlocomotion induced by dopamine receptor agonists [7]. Thus, the diminished effect of caffeine in $\beta_{25-35}$-treated mice could reflect a diminished influence of adenosine in the ventral striatum, resembling the situation of caffeine-tolerant mice [20].

As intracerebroventricular $\beta_{25-35}$ microinjection causes significant hippocampal alterations in mice [13], our results can be compared to other lesion models. Hippocampal lesion with ibotenic acid in adult animals increased both spontaneous locomotion and the effects of amphetamine [10], with no effect on the response to MK801 in adult animals [21], while aspirative hippocampal lesions also induced a higher response to amphetamine, mostly mediated by dopamine D2 receptors [22]. In contrast, when the ventral hippocampus is lesioned during the early neonatal period, which is a neurodevelopmental model for schizophrenia, adult animals show increased response to both amphetamine and MK-801 [23].

Further studies will be necessary to clarify if there is a similar response in transgenic models of $\mathrm{AD}$ with slow deposition of $\beta$-amyloid. At this point, our study showed that $\beta$-amyloid-treated mice showed memory impairment as well as locomotor alterations similar to other hippocampal-damage models, with higher spontaneous locomotion and response to amphetamine, possibly related to 
a reduced adenosinergic tone. Since hyperlocomotion is a behavioral parameter thought to relate to psychotic symptoms in humans, these results are in line with the frequent manifestation of delusions and hallucinations as well as psychomotor agitation in AD patients.

\section{Acknowledgments}

This study was supported by PRONEX (grant 41960604-366/96), CNPq and FAPERGS.

\section{References}

$>1$ Cummings JL: Cognitive and behavioral heterogeneity in Alzheimer's disease: Seeking the neurobiological basis. Neurobiol Aging 2000; 21:845-861.

$\checkmark 2$ Chui HC, Lyness SA, Sobel E, Schneider LS: Extrapyramidal signs and psychiatric symptoms predict faster cognitive decline in Alzheimer's disease. Arch Neurol 1994;51:676681.

3 Kapur S, Seeman P: Ketamine has equal affinity for NMDA receptors and the high-affinity state of the dopamine D2 receptor. Biol Psychiatry 2001;49:954-957.

4 Krystal JH, D’Souza DC, Karper LP, Bennett A, Abi-Dargham A, Abi-Saab D, Cassello K, Bowers MB Jr, Vegso S, Heninger GR, Charney DS: Interactive effects of subanesthetic ketamine and haloperidol in healthy humans. Psychopharmacology (Berl) 1999;145:193204.

$\checkmark 5$ Kapur S, Seeman P: Does fast dissociation from the dopamine $d(2)$ receptor explain the action of atypical antipsychotics? A new hypothesis. Am J Psychiatry 2001;158:360-369.

6 Hollingsworth EM, Mueller K: Patterns of locomotor and stereotypic behavior during continuous amphetamine administration in rats Pharmacol Biochem Behav 1988;30:535-537.

7 Ferre S, Fredholm BB, Morelli M, Popoli P, Fuxe K: Adenosine-dopamine receptor-receptor interactions as an integrative mechanism in the basal ganglia. Trends Neurosci 1997;20 482-487.

-8 Fredholm BB, Battig K, Holmen J, Nehlig A, Zvartau EE: Actions of caffeine in the brain with special reference to factors that contribute to its widespread use. Pharmacol Rev 1999;51: 83-133. $\checkmark 9$ Ellenbroek BA: Treatment of schizophrenia: A clinical and preclinical evaluation of neuroleptic drugs. Pharmacol Ther 1993;57:1-78.

10 Wood GK, Lipska BK, Weinberger DR: Behavioral changes in rats with early ventral hippocampal damage vary with age at damage. Brain Res Dev Brain Res 1997;101:17-25.

11 Morris JC, Price AL: Pathologic correlates of nondemented aging, mild cognitive impairment, and early-stage Alzheimer's disease. J Mol Neurosci 2001;17:101-118.

12 Kowall NW, McKee AC, Yankner BA, Beal MF: In vivo neurotoxicity of beta-amyloid [beta(1-40)] and the beta(25-35) fragment. Neurobiol Aging 1992;13:537-542.

13 Maurice T, Lockhart BP, Privat A: Amnesia induced in mice by centrally administered beta-amyloid peptides involves cholinergic dysfunction. Brain Res 1996;706:181-193.

14 Yamada K, Tanaka T, Senzaki K, Kameyama $\mathrm{T}$, Nabeshima T: Propentofylline improves learning and memory deficits in rats induced by beta-amyloid protein-(1-40). Eur J Pharmacol 1998;349:15-22.

15 Harkany T, Hortobagyi T, Sasvari M, Konya C, Penke B, Luiten PG, Nyakas C: Neuroprotective approaches in experimental models of beta-amyloid neurotoxicity: Relevance to Alzheimer's disease. Prog Neuropsychopharmacol Biol Psychiatry 1999;23:963-1008.

16 Bussiere T, Friend PD, Sadeghi N, Wicinski B, Lin GI, Bouras C, Giannakopoulos P, Robakis NK, Morrison JH, Perl DP, Hof PR: Stereologic assessment of the total cortical volume occupied by amyloid deposits and its relationship with cognitive status in aging and Alzheimer's disease. Neuroscience 2002;112:7591.

17 Olariu A, Tran MH, Yamada K, Mizuno M, Hefco V, Nabeshima T: Memory deficits and increased emotionality induced by beta-amyloid (25-35) are correlated with the reduced acetylcholine release and altered phorbol dibutyrate binding in the hippocampus. $\mathrm{J}$ Neural Transm 2001;108:1065-1079.
18 Tremml P, Lipp HP, Muller U, Ricceri L, Wolfer DP: Neurobehavioral development, adult openfield exploration and swimming navigation learning in mice with a modified beta-amyloid precursor protein gene. Behav Brain Res 1998;95:65-76.

19 Hillion JA, Canals M, Torvinen M, Casado V Scott R, Terasmaa A, Hansson A, Watson S, Olah ME, Mallol J, Canela EI, Zoli M, Agnati LF, Ibanez CF, Lluis C, Franco R, Ferre S, Fuxe K: Coaggregation, cointernalization and codesensitization of adenosine $\mathrm{A} 2 \mathrm{~A}$ receptors and dopamine D2 receptors. J Biol Chem 2002;277:18091-18097.

20 Svenningsson P, Nomikos GG, Fredholm BB: The stimulatory action and the development of tolerance to caffeine is associated with alterations in gene expression in specific brain regions. J Neurosci 1999; 19:4011-4022.

21 Al Amin HA, Shannon WC, Weinberger DR, Lipska BK: Delayed onset of enhanced MK801-induced motor hyperactivity after neonatal lesions of the rat ventral hippocampus. Biol Psychiatry 2001;49:528-539.

22 Mittleman G, LeDuc PA, Whishaw IQ: The role of D1 and D2 receptors in the heightened locomotion induced by direct and indirect dopamine agonists in rats with hippocampal damage: An animal analogue of schizophrenia. Behav Brain Res 1993;55:253-267.

23 Lipska BK, Jaskiw GE, Chrapusta S, Karoum F, Weinberger DR: Ibotenic acid lesion of the ventral hippocampus differentially affects dopamine and its metabolites in the nucleus accumbens and prefrontal cortex in the rat. Brain Res 1992;585:1-6. 